\title{
ENTRE MALUCOS E MILICOS: ETNOGRAFIA, ESTEREÓTIPOS \\ FAMILIARES E PAPEL DA MULHER NAS RELAÇÕES DE CUIDADO
}

\section{Sílvia Monnerat ${ }^{1}$}

Este artigo tem como objetivo principal a realização de um esforço interpretativo sobre questões concernentes às relações familiares vividas por interlocutores de pesquisa pertencentes a diferentes contextos sociais, oriundos das camadas médias do Rio de Janeiro. As observações participantes que balizam o texto aqui apresentado são fruto de pesquisas desenvolvidas com: 1) pacientes de um núcleo de atenção à saúde mental particular localizado na zona sul do Rio de Janeiro e, 2) oficiais do exército brasileiro residentes na cidade do Rio de Janeiro.

Esses dois campos não foram escolhidos aleatoriamente, eles se relacionam e se distanciam em diversas esferas (como veremos a seguir), a começar pela trajetória da própria autora: o campo primeiramente descrito foi aberto por mim em 2009, por ocasião de minha pesquisa de doutorado em Antropologia Social, defendida no Museu Nacional da UFRJ (Monnerat, 2014), quando iniciei um estudo sobre relações familiares de pacientes psiquiátricos em duas instituições de cuidado à saúde mental, uma pública e uma particular (esta última, aqui alvo de análise). O segundo campo se refere ao trabalho desenvolvido desde janeiro de 2015 no Laboratório de Estudo sobre Militares (CPDOC/FGV), onde atuo como pesquisadora bolsista e realizo estudo sobre relações familiares de oficiais do exército que residem no Rio de Janeiro.

Utilizo, de maneira proposital, no título deste trabalho, duas categorias que marcam estereótipos relacionados aos universos estudados. A utilização desses termos: malucos e milicos se relaciona, em primeira instancia, ao próprio fazer etnográfico. Em ambos os casos, durante o período de aproximação com o campo, presumi que esses fossem termos tabus, e, portanto, que não fossem rotineiramente utilizados por meus interlocutores. Logo no primeiro mês trabalhando com esses universos, no entanto, pude observar que essas categorias eram utilizadas mais ou menos rotineiramente por pesquisadores e outros interlocutores de pesquisa. Como a intenção aqui é pensar as formas de organização familiar, parece-me oportuno utilizar esses termos,

\footnotetext{
${ }^{1}$ Universidade Federal do Rio de Janeiro e Fundação Getúlio Vargas, Brasil.
} 
estereotipados (como o subtítulo deste artigo indica) que são capazes de explicitar noções de senso-comum ${ }^{2}$ sobre os dois universos.

Tratando-se de um estudo epistemológico, em que o próprio fazer da pesquisa é alvo de análise, propõe-se aqui, então, expor percursos percorridos e realizar uma discussão sobre métodos e técnicas de pesquisa no âmbito dos estudos sobre família. Assim sendo, a presente pesquisa tem como objetivo pensar o próprio fazer etnográfico, sua prática, suas dificuldades e seus avanços, reforçando que se faz necessário, para tanto, o exercício constante de reflexão sobre como as relações em campo são construídas. O trabalho aqui apresentado se configura, portanto, em um esforço de ampliação da lente de análise, procurando sair de um olhar voltado para etnografias específicas sobre "família louca" (Monnerat, 2014) e/ou "família militar" (Castro e Leirner, 2009) e pensar de maneira mais ampla as dificuldades, semelhanças e distinções existentes ao se estudar famílias, em seus mais diversos campos.

Utilizo, como critério mais geral de comparação, o fato das pesquisas serem realizadas com indivíduos pertencentes às camadas médias do Rio de Janeiro (famílias de pacientes que realizavam tratamento em instituição particular na zona sul do Rio de Janeiro e famílias de oficiais do exército residentes na mesma cidade), para que, assim, condicionantes de classe, origem social e renda não venham a produzir biases para as análises aqui propostas ${ }^{3}$.

Não pretendo chegar aqui a uma definição única de família (até porque a bibliografia sobre o tema aponta existência de inúmeros e distintos arranjos familiares em nossa sociedade ${ }^{4}$ ), e sim discutir como diferentes famílias se entendem, se significam e quais sistemas e redes englobantes podem ser relacionadas à elas. Ou seja, busco, neste estudo, trabalhar com as representações sociais que eles fazem sobre suas famílias.

\footnotetext{
${ }^{2}$ Sobre construções de senso-comum recorro a Schutz (2014: 51): "A especificidade das ciências sociais estaria no fato de que o campo de observação do cientista social - a realidade social - tem um significado prévio para ele próprio e para as pessoas que são objeto da investigação. O cientista social, desse modo, interpretaria 'constructos de segundo grau' em relação ao conhecimento de 'primeiro grau' do sensocomum, trabalhando sobre as interpretações subjetivas dos vários atores sobre a realidade social (inclusive e necessariamente as dele próprio)".

${ }^{3}$ Parte-se aqui do pressuposto, assim como o fez Bilac (1995: 45), que "a problemática da família estaria se constituindo diferentemente nas diferentes classes e grupos sociais e, por isso mesmo, demandaria abordagens diferenciadas".

${ }^{4}$ Para mais informações, ver: Ribeiro, Ivete e Ribeiro, Ana Clara Torres. Famílias em processos contemporâneos: inovações culturais na sociedade brasileira. São Paulo: Loyola, 1995.
} 
Sublinha-se, também, que os casos aqui estudados tendem a parecer para o senso-comum, ao menos em um primeiro momento, como antagônicos entre si, por representarem ideais sociais considerados opostos. Enquanto as famílias de pacientes psiquiátricos tendem a ser entendidas como conflituosas, doentes e caóticas, as relações familiares de oficiais costumam ser entendidas como regradas e disciplinadas. Dessa forma, esses dois tipos de família representariam um "tipo ideal" 5 , que espelharia as representações de senso-comum de seu próprio grupo englobante: a família de pacientes psiquiátricos seria entendida como louca (como apontei em minha tese de doutorado) ${ }^{6} \mathrm{e}$ a família de militares tende a ser apontada como um reflexo dos ideais da caserna (como demonstra a bibliografia sobre o assunto) ${ }^{7}$.

Ao aprofundar a análise e buscar proposições comuns a estes dois universos, foi possível perceber que esses dois tipos de organização familiar são permeados por características comuns, principalmente no que se refere ao lugar social que a mulher/mãe ocupa na família, notoriamente relacionado ao papel de cuidadora (da família e do lar). As relações de gênero, dessa forma, se delineiam como o fio central desta pesquisa, principalmente no que tange às relações de cuidado. $\mathrm{O}$ esforço empreendido neste estudo segue, portanto, na direção de construção de uma visão mais ampla sobre relações familiares, partindo de um olhar comparativo entre esses dois campos de estudo, buscando aproximações e distinções entre eles.

\footnotetext{
${ }^{5}$ Segundo Weber (2014: 57): "Obtém-se um tipo ideal mediante a acentuação unilateral de um ou vários pontos de vista e diante o encadeamento de grande quantidade e fenômenos isoladamente dados, difusos e discretos, que se podem dar em maior ou menor número ou mesmo faltar por completo, e que se ordenam segundo os ponto de vista unilateralmente acentuados, a fim de se formar um quadro homogêneo de pensamento".

6 "[A]o se questionar se há um louco na família ou se a família é louca, coloca-se em evidência o processo de responsabilização da mesma, pois a existência de um doente mental indicaria, segundo os discursos encontrados em campo, que a família se encontra doente de alguma forma, seja por estar transmitindo os genes responsáveis pela doença, seja pela existência de ambiente familiar conflituoso, agressivo e/ou simbiótico que fez com que a doença viesse a se manifestar." (Monnerat, 2014: 86).

${ }^{7}$ Segundo Chinelli (2009: 97), em seu estudo sobre mulheres de militares: o "ethos militar extrapola os aspectos profissionais e penetra na vida doméstica. Assim, há um incentivo formal por parte da corporação à confraternização e à união entre os membros da chamada 'família militar'". Outra estudiosa das relações familiares de oficias do exército, Silva (2009: 124) afirma que: "os dados até agora mostram que a expressão 'família militar' é tida como um conceito nativo e significa para os militares tanto a identidade do grupo (a instituição militar como um todo) quanto o valor da família como suporte para a vida. Logo, a 'família militar' apresenta características que são definidas sobretudo por normas e condutas da instituição militar, sugerindo a ideia de que a família possa ser uma extensão do quartel, que se reflete na organização da moradia e do cotidiano dessas pessoas, marcado, segundo elas, por um convívio maior com famílias do mesmo círculo hierárquico do cônjuge militar e por dificuldades comuns, devido à frequente mobilidade geográfica a que o oficial de carreira é submetido".
} 
$\mathrm{Na}$ antropologia são conhecidos os debates conceituais em torno das diferentes noções de família, no entanto, nos campos estudados, as pesquisas sobre relações familiares ainda não são tão fecundas e carecem de maior investimento analítico. Mesmo não sendo objetivo central realizar aqui uma exaustiva revisão desta questão conceitual, entende-se, todavia, ser fundamental trazer algumas referências e definições sobre modelos familiares para que se possa melhor situar o estudo aqui proposto.

Para tanto, recorro primeiramente ao enunciado por Luiz Fernando Dias Duarte, no artigo intitulado "Nós na família", veiculado em sua coluna mensal na Revista "Ciência Hoje". Neste texto, o autor evidencia que "[e]ntre as múltiplas ordens de englobamento das pessoas socialmente situadas, a família tem uma posição privilegiada", pois ela é entendida como uma "trama que envolve os sujeitos na sua socialização primária" e, tal como exposto pela experiência analítica da antropologia, observa-se que "mesmo em nossas sociedades, e a despeito do vigor da ideologia do individualismo, o pertencimento familiar continua sendo uma dimensão crucial da experiência social". Dessa forma, ainda segundo Duarte, "[p]or mais que nos representemos autônomos ou autonomizados em relação a elas, sempre portamos uma dimensão de participação, pertencimento, englobamento e entranhamento que nos mantêm no interior daquela configuração" (Duarte, 2012).

Assim sendo, entende-se família como um princípio de construção da realidade social, oriundo do processo de socialização. A instituição familiar, nesse sentido, não pode ser considerada como um dado imediato da realidade social, mas sim como um instrumento de construção dessa realidade que possui "papel determinante na manutenção da ordem social, na reprodução, não apenas biológica, mas social, isto é, na reprodução da estrutura do espaço social e das relações sociais" (Bourdieu, 1996: 131).

Dessa forma, tal como sugeriu Sarti (2004: 13), busca-se, também na pesquisa aqui apresentada,

\footnotetext{
"uma abordagem de família como algo que se define por uma história que se conta aos indivíduos desde que nascem, ao longo do tempo, por palavras, gestos, atitudes ou silêncios e que será, por eles, reproduzida e re-significada, à sua maneira, dados os distintos lugares e momentos dos indivíduos na família. Vista como uma realidade que se constitui pela linguagem, socialmente elaborada e internalizada pelos indivíduos, a família torna-se um campo privilegiado para se pensar a relação entre o individual e o coletivo".
} 
Com base na bibliografia consultada e nos trabalhos etnográficos realizados, percebe-se a complexidade de estudar relações familiares. Entrar nesse campo, por si só, não é uma tarefa fácil, sua abertura pressupõe o aceite de seus membros e o acesso a informações íntimas (e muitas vezes sigilosas). Assim sendo, os estudiosos que se propõe a desenvolver trabalhos com este foco, se deparam com a dificuldade de acessar essas histórias (contadas ao longo do tempo no seio familiar), assim como os conflitos intrafamiliares cotidianos e as situações extra-ordinárias ocorridas. Seja pelo esquecimento ou pela imagem que pretendem passar, as histórias que chegam aos pesquisadores interessados em essas relações são sempre permeadas por imagens que os interlocutores fazem de suas próprias famílias, misturadas a "tipos [familiares] ideais", fazendo com que, muitas vezes, essas representações se confundam.

Dessa forma, o primeiro desafio metodológico no campo, refere-se às dificuldades de se inserir em redes familiares distintas da sua de origem. Cada campo, como será visto adiante, demanda desafios próprios para a inserção e interação, afinal alguns grupos são de mais difícil acesso do que outros (talvez em reflexo ao próprio fechamento da instituição na qual estão inseridos, como no caso do exército). Assim sendo, o pesquisador deve ser criativo, buscando estratégias para a aproximação e interação própria com o campo, possibilitando, assim, que as informações obtidas sejam condizentes com as situações vividas e sentidas pela rede familiar e não apenas retratem uma idealização dessa organização. Para tanto, um constante exercício de reflexão sobre o fazer etnográfico se torna fundamental: conhecer o campo de possibilidades existente para o desenvolvimento da pesquisa e as estratégias e técnicas possíveis para chegar às histórias de vida dessas pessoas é necessário, mesmo sabendo que as histórias e vivencias que chegam até os pesquisadores serão sempre incompletas, fragmentadas e sujeitas a re-significações, afinal acessamos apenas aquilo que é evidenciado pelos interlocutores, seja através de suas falas, gestos ou silêncios.

\section{II}

Na bibliografia consultada sobre "família militar", a dificuldade de acesso e o tempo de inserção em campo foram apontados e problematizados como fatores dificultadores para um aprofundamento sobre representações familiares de oficiais do exército (Chinelli, 2008; Silva, 2010). Outro ponto enfocado por essa bibliografia (que também se relaciona a questão do tempo de contato com os interlocutores) refere-se à 
existência de uma padronização de respostas sobre relações familiares. Essa padronização parece indicar que os discursos proferidos se coadunam com o ideal de família propagado pelo ethos militar, fazendo com que os interlocutores tentem, aparentemente, se enquadrar nesse ideal.

Partindo dessa premissa, cada um dos casos estudados poderia até ser pensado como localizado em um dos extremos de um continuum, que iria do caos completo à ordem total. Essa perspectiva parece encontrar ressonância nas representações sobre família (de maneira geral) presentes nas formulações de senso-comum (ou "constructos de primeiro grau", nos termos de Schutz). No entanto, por se tratar de um trabalho etnográfico, que opera com construções de "segundo grau" (focadas, portanto, nos elementos subjetivos, referidos aos diferentes pontos de vista em jogo durante as situações de interação), se preocupa com as diferenças e multiplicidades observadas nos campos estudados.

Dados etnográficos evidenciaram, por exemplo, que no campo realizado com pacientes psiquiátricos existiam arranjos familiares cujas relações poderiam ser consideradas harmônicas e não baseadas apenas em conflitos. $\mathrm{O}$ reconhecimento da diversidade e das restrições do outro se mostraram como peça-chave para o desenvolvimento de tais relações (perpassadas por conflitos ou angústias, mas baseadas no amor e na compreensão). No campo com militares, também foi verificada a existência de representações diversas sobre relações familiares. Uma entrevistada, por exemplo, ao ser perguntada sobre a existência, ou não, de graves conflitos vividos por famílias de militares, me contou a história de um oficial que ela conhecia que, por não ter recebido a promoção para general, teria planejado juntamente com sua esposa o suicídio dos dois. Salienta-se, então, que tanto a "família militar", quanto a "família louca", só podem ser pensadas em termos de um continuum, quando analisadas nos termos de constructos de "primeiro-grau" (Schutz, 2014: 53) e não quando analisados pelos constructos de "segundo-grau", tal como se expressa o conhecimento oriundo do pensamento científico, sob olhar das ciências sociais ${ }^{8}$.

\footnotetext{
${ }^{8}$ Segundo Schutz (2014: 53): "O campo de observação do cientista social, no entanto, ou mais precisamente a realidade social, tem um significado específico e uma estrutura de relevância para os seres humanos que vivem, agem e pensam dentro dele. Através de uma série de construções do senso-comum, eles previamente selecionaram e interpretaram esse mundo que vivenciam como a realidade de suas vidas diárias. São esses seus objetos de pensamento que determinam seu comportamento, motivando-o. Os objetos de pensamento construídos pelo cientista social para captar essa realidade social têm que ser fundamentados nos objetos de pensamento construídos pelo pensamento do senso-comum dos homens
} 
Levando isso em conta, caberia, então, ao pesquisador (que se propõe a estudar relações familiares), não se limitar às construções gerais propagadas pelo senso-comum, buscando observar e analisar elementos subjetivos oriundos dessas relações e, assim, formular "constructos sobre os constructos formados no pensamento de senso-comum" (Schutz, 2014: 55). Desse modo, não devemos basear nossas análises em proposições universais do que seria uma "família louca", "família militar" ou, de maneira mais geral, uma "família brasileira de classe média", e sim procurar acessar como "famílias de militares", ou "famílias de pacientes psiquiátricos", ou "famílias de classe média" se significam e se representam. Para tanto é necessário estar atento às visões de sensocomum propagadas por eles, assim como às possíveis dissonâncias existentes ao se comparar com tipos ideais.

Busco, então, aqui, tal como expôs Velho (2013: 53), analisar as relações sociais existentes entre meus interlocutores sobre uma ótica em que

\begin{abstract}
"todas as sociedades apresentem formas de controlar os seus conflitos, variando os meios e a eficácia relativa. Mas em toda vida social existe a permanente possibilidade do dissenso. Assim, em vez de se partir de uma hipotética "normalidade harmoniosa", tem-se que admitir a permanente existência de contradições. Estas podem manifestar-se, em nível mais amplo, em termos de conflito entre os principais grupos constituintes da sociedade (...) e manifestam-se também no nível microssocial em termos de conflito entre papéis, como os de pai e filho, marido e mulher, irmão e irmã etc".
\end{abstract}

Dessa forma, interessa-nos superar a "hipotética "normalidade harmoniosa"”, da "família militar" através do desenvolvimento de uma pesquisa de longa duração e, a partir daí, observar a existência de conflitos internos cotidianos (como doenças, brigas, descontroles e discordâncias na criação dos filhos e no cuidado com a casa) comuns a relações familiares.

Questões referidas na bibliografia consultada sobre as dificuldades de entrada nesse campo trouxeram certa inquietação, que resultou nas reflexões aqui expostas, já que, logo no primeiro mês em campo, uma diferença entre os dois grupos estudados se tornou gritante. Com os pacientes psiquiátricos, os problemas, doenças e desvios eram esperados e logo surgiam nas falas de meus interlocutores. Tratava-se de famílias que

que vivem sua vida diária dentro do seu mundo social. Assim, os constructos das ciências sociais são, por assim dizer, constructos de segundo grau, ou seja, constructos dos constructos feitos pelos atores no cenário social, cujo comportamento o cientista social tem de observar e explicar de acordo com as regras de procedimento da sua ciência". 
tinham pelo menos um de seus membros diagnosticados com transtorno mental grave e que realizava tratamento psiquiátrico em instituição de atenção à saúde mental. Nesse caso, a minha aproximação com os familiares (via instituição) era permeada por um problema já dado, a saber, a relação com a doença e com as limitações e encargos trazidas por ela. Assim sendo, a dificuldade de ter acesso a significações nativas sobre determinadas situações vividas no âmbito familiar (como tentativas de suicídio, questões relacionadas à agressividade e/ou vícios) até existiam, mas normalmente, em algum momento, essas representações eram trazidas para a fala, mesmo que sem um grande aprofundamento (seja pelo paciente, seja por membros de sua família).

Levanto como hipótese o fato de que, como o desvio já era de meu conhecimento (via prontuário, pacientes ou técnicos do serviço), os interlocutores acabavam por falar sobre o assunto - bem mais do que em um campo onde os conflitos tendem a se configurar como um segredo de família, tal como exposto por uma interlocutora de pesquisa, viúva de um oficial reformado do exército, residente na zona sul do Rio de Janeiro:

\begin{abstract}
"Olha, por exemplo, se uma [esposa] precisasse tomar remédio controlado, ninguém devia saber. Porque? Porque iam dizer que ela estava maluca, que tinha problemas de nervos, né? Problemas nervosos. Ou, filhos... tinha que esconder aquilo tudo". “(...) não interessava para o exército ter uma pessoa doente, né”. [Era comumente dito, nesses casos:] "A mulher dele não bate bem da cabeça, a mulher dele é histérica ou coisa parecida".
\end{abstract}

Como no depoimento acima citado, percebe-se que no campo com os militares (e seus familiares) a tarefa de acessar questões relacionadas a algum desvio referido ao seu núcleo familiar (que destoe do ideal da "família militar") pode não ser tão fácil, uma vez que, nesse universo, eles tendem a ser vistos como um segredo a ser mantido no seio familiar, de forma que não atrapalhe a progressão profissional do militar.

Essas diferenças, referentes às possibilidades de acesso às informações em campo, evidenciam que, por mais que a pesquisadora estivesse familiarizada com estudos sobre relações familiares e, de certa forma, achasse que sabia, mais ou menos, o que esperar das famílias estudadas (principalmente no que dizia respeito às questões de gênero relacionadas ao cuidado e ao papel que a maternidade assume para as mulheres em nossa sociedade), novas questões surgiram e um grande estranhamento emergiu. Seriam tão harmônicas assim as famílias de militares? Como a questão das mudanças e do distanciamento da família de origem incidiria sobre as configurações familiares 
formadas por oficiais militares? Como eles lidariam com casos desviantes (doenças mentais, homossexualidade, adicção em drogas etc)?

Essas questões ainda não serão respondidas, mas elas norteiam a pesquisa ora em desenvolvimento e, devido a isso, reforço, me utilizando das palavras de Gilberto Velho (2013: 74), que

\begin{abstract}
"Posso estar acostumado (...) com uma certa paisagem social onde a disposição dos atores me é familiar; a hierarquia e a distribuição de poder permitem-me fixar, grosso modo, os indivíduos em categorias mais amplas. No entanto, isso não significa que eu compreenda a lógica de suas relações. O meu conhecimento pode estar seriamente comprometido pela rotina, hábitos, estereótipos. Logo, posso ter um mapa mas não compreendo necessariamente os princípios e mecanismos que o organizam"
\end{abstract}

Tendo essa perspectiva em mente é que este trabalho, de cunho mais metodológico, surgiu. Se já me encontrava estudando relações familiares, por ocasião do inicio do trabalho no Laboratório de Estudos sobre Militares, isso não quer dizer que estivesse familiarizada com a lógica das relações vividas por oficiais (os princípios e mecanismos que as organizam), uma vez que essa lógica pode se aproximar ou se distanciar das encontradas no campo anteriormente realizado. Dessa forma, tal como indicou Lévi-Strauss em seu artigo "La famille" [A família], deve-se estar sempre atento aos perigos que a pretensa familiaridade com o assunto pode trazer, pois pode levar a generalizações simplificadoras do universo mais amplo que pretendo focar. Para a solução desse problema, o autor sublinha a necessidade de um contínuo exercício de reflexão problematizadora em todas as etapas da pesquisa.

\title{
III
}

Como disse anteriormente, na pesquisa com militares me encontro em fase exploratória e, devido a isso, é necessário um maior tempo de trabalho de campo para poder acessar as vicissitudes familiares e chegar a conclusões finais (ou mesmo relacionar minhas hipóteses à considerações mais específicas sobre o tema). Durante o trabalho de campo com pacientes psiquiátricos, passei três anos frequentando a instituição onde eles realizavam tratamento e participando das reuniões de familiares ${ }^{9}$,

\footnotetext{
${ }^{9}$ Além do trabalho etnográfico realizado nessa instituição particular de atenção à saúde mental, realizei quatro anos de observação participante em instituição pública também de atenção à saúde mental (no âmbito de minha pós-graduação) e coordenei durante dois anos e meio um curso desenvolvido pelo 
tendo, dessa forma, uma aproximação de longa duração com meus interlocutores, o que deverá ocorrer também no campo em que agora me encontro.

Essa consideração nos leva a outra recomendação metodológica para estudos com e sobre famílias: pesquisas curtas ou exploratórias não trarão uma densidade de dados que a proximidade e o longo tempo de observação e interação podem proporcionar. Lógico que a revisão da bibliografia sobre o assunto (em especial outras etnografias desenvolvidas) pode trazer pistas interessantes que ajudem na construção de hipóteses, mas o que quero reforçar aqui é que o desenvolvimento de uma etnografia de longa duração possibilita a diminuição de biases de pesquisa, afinal, tal como enfatizou Becker (1977: 84):

\footnotetext{
"o observador de campo tipicamente coleta seus dados por um período prolongado de tempo, em uma variedade de situações, usando diversas maneiras de chegar à questão em que está interessado; todos estes aspectos que reduzem o perigo do bias. Por observar durante um período longo de tempo, ele terá dificuldade de ignorar a massa de informações que sustenta uma hipótese apropriada que ele pode nem ter esperado ou desejado, do mesmo modo que as pessoas que estuda teriam dificuldade, se quisessem enganá-lo, de manipular tal massa de impressões a ponto de afetar sua visão da situação".
}

Dessa forma, ainda segundo o exposto por Becker (1977: 79), os pesquisadores que se propõem a estudar relações familiares devem manter em mente que os "valores de qualquer grupo social são um ideal do qual o comportamento real pode às vezes se aproximar, mas raramente incorpora integralmente" e lembrar que "[e]m muitas situações, os entrevistados o percebem [entrevistador] como pessoa potencialmente perigosa e, temendo que descubra segredos que seria melhor esconder do mundo exterior, lançam mão da 'linha oficial' para manter seu esforço inquisitivo delicadamente à distancia." (1977: 80). Dentro desta perspectiva analítica, se reforça a necessidade de um trabalho etnográfico de longa duração, para que os interlocutores se sintam confortáveis com a sua presença e à vontade para falar de suas questões cotidianas, incluindo aí os conflitos e dificuldades inerentes às relações familiares. Assim sendo, acredita-se que uma pesquisa realizada segundo critérios éticos e metodológicos da etnografia podem sanar (ou, ao menos, diminuir) essa aparente dificuldade em acessar as histórias (de vida e familiares) mais íntimas, evitando, assim, ocultações e silêncios (ou, mesmo sem superá-los, possibilitar seus entendimentos) que,

Instituto de Psiquiatria da UFRJ para familiares de pacientes psiquiátricos pertencentes há aproximadamente 20 Centros de Atenção Psicossocial da região metropolitana do Rio de Janeiro. 
nos casos aqui estudados, podem estar referidos ao pertencimento a "instituições totalizantes" (Castro, 2007), cujos papeis sociais são marcados e, até certo ponto, englobantes.

Outro ponto fundamental ao estudar famílias, relaciona-se ao fato de se lidar constantemente com silêncios, ocultações e contradições trazidas pelos interlocutores de pesquisa. Como acessar as histórias da forma como se passaram de fato? E possível conhecer toda a história de uma pessoa ou de uma família? Como lidar com diferentes versões sobre os mesmos fatos? Existe uma história "real" ou apenas versões que chegam a nós - cabendo, aí, ao pesquisador, seguir as diferentes trilhas analíticas possíveis e construir a sua própria interpretação dos fatos?

Para responder a tais perguntas é interessante recorrer ao enunciado por Velho (2013: 67), que sustenta que:

\begin{abstract}
"A memória é fragmentada. O sentido de identidade depende em grande parte da organização desses pedaços, fragmentos de fatos e episódios separados. O passado, assim, é descontínuo. A consistência e o significado desse passado e da memória articulam-se à elaboração de projetos que dão sentido e estabelecem continuidade entre esses diferentes momentos e situações".
\end{abstract}

E também que:

\begin{abstract}
"São verdadeiros personagens que marcam o trabalho do antropólogo. (...). Esse contato pessoal, direto, faz com que os padrões de objetividade científica tradicionais tenham de ser encarados com certa reserva. Por isso mesmo, o trabalho do antropólogo tende a assumir cada vez mais a dimensão da instersubjetividade. Não se trataria, então, de procurar abstrair os aspectos individuais, idiossincrasias pessoais etc., mas sim de procurar encará-los como parte da situação de pesquisa. Em vez de apagar esta dimensão 'psicológica', tarefa realmente impossível, resta aprender a explicitá-la e integrá-la a toda a investigação. Assim, mais uma vez, a procura de padrões sociais e culturais não implicaria um 'pôr entre parênteses' a dimensão individual. Isto significa, de um lado, o antropólogo aprender a lidar com a sua subjetividade e, de outro, a considerar mais relevantes para o seu trabalho características 'estritamente individuais' das pessoas com quem está convivendo" (2013: 49).
\end{abstract}

Com essas longas citações, pretendo frisar o papel da inter-subjetividade na construção das relações sociais que emergem durante o desenvolvimento de uma pesquisa qualitativa que, em grande medida, condiciona o acesso que você vai ter às informações disponibilizadas pelos interlocutores de pesquisa (as "verdades" e os "silêncios" que chegam ao antropólogo em campo). O fazer etnográfico deve ser objeto de reflexão constante por parte do pesquisador, sua subjetividade e a subjetividade de seus interlocutores se configuram como o próprio objeto de estudo. Os biases da 
pesquisa qualitativa são condicionados por essa inter-subjetividade e devem ser explicitados para que as análises e conclusões não soem como inventadas e sim como fruto da relação dialógica estabelecida entre pesquisador e pesquisados.

Dessa forma, voltando ao embricamento entre a visão de si e das relações familiares em relação ao ideal de família projetado (por si e pelo senso-comum), ideal este muitas vezes visto como um espelho das "instituições totalizantes" das quais o pesquisado faz parte, podemos recorrer a Leirner (1993: 13), quando ele observa, em seu estudo sobre hierarquia militar, que "além da carga da instituição que o indivíduo traz consigo, também a instituição carrega consigo a ideia de indivíduo como elemento capaz de representar a instituição" (1996: 13). Assim sendo, em estudos como o aqui proposto, é necessário considerar que indivíduos fazem parte de instituições sociais e esse pertencimento pode levar a uma sobreposição entre o que se espera do indivíduo e/ou da instituição, uma vez que um buscaria representação no outro. A percepção de si, feita pelos membros da família tende a se confundir, então, com o senso-comum que vigora em seu meio: quando a relação se dá em uma instituição de saúde mental e, assim, os tópicos de conversas tendem a girar em torno da doença, do cuidado e das dificuldades enfrentadas no dia-a-dia, o pesquisador tem acesso a um tipo de informação em que os conflitos saltam aos olhos; quando o campo é entendido como um ambiente que propicia relações disciplinadas, ordenadas e normativas, as informações e expectativas em relação à construção de si são outras e as informações que chegam ao pesquisador também. Assim sendo, silêncios e ocultamentos podem representar coisas distintas em cada um dos casos, cabe ao pesquisador pensar estratégias úteis para significar esses silêncios, assim como para alcançar verbalizações sobre assuntos íntimos e familiares. Para pensar tais questões, recorro, então, a Pollack (1989: 7), quando este sustenta que:

\footnotetext{
"A fronteira entre o dizível e o indizível, o confessável e o inconfessável, separa, em nossos exemplos, uma memória coletiva subterrânea da sociedade civil dominada ou de grupos específicos, de uma memória coletiva organizada que resume a imagem que uma sociedade majoritária ou o estado desejam passar e impor".
}

Assim, para uma melhor compreensão sobre a relação estabelecida com os interlocutores de uma pesquisa, é fundamental ter conhecimento sobre o universo vivido por eles, as instituições das quais fazem parte e as noções de senso-comum que são evocadas ao se falar dessas instituições e pessoas. Dessa forma, assim como sublinhou 
Leirner (1996), “[e]ste olhar que oferece o confronto entre o discurso e conduta, representação e ação - o osso, carne e espírito malinowskianos -, neste caso, nos permitiu pensar, inclusive, no significado do silêncio".

Esta perspectiva aponta, mais uma vez, para a importância da imersão no campo (para conhecê-lo de maneira mais abrangente), além da necessidade de realização de um trabalho de longa duração, fazendo com que o pesquisador se torne conhecido e próximo de seus interlocutores, possibilitando, assim, acessar de maneira mais horizontal as histórias familiares. Seguindo as palavras de Velho, insisto

\begin{abstract}
"na ideia de que para conhecer certas áreas ou dimensões de uma sociedade é necessário um contato, uma vivência durante um período de tempo razoavelmente longo, pois existem aspectos de uma cultura e de uma sociedade que não são explicitados, que não aparecem à superfície e que exigem um esforço maior, mais detalhado e aprofundado de observação e empatia" (2013: 69).
\end{abstract}

Estou salientando aqui, então, a importância de um trabalho de aprofundamento analítico sobre os indivíduos alvo de estudo, assim como sobre as instituições sociais das quais eles fazem parte, gerando conhecimento condizente com a realidade vivida.

\title{
IV
}

Por fim, gostaria de discutir o papel da mulher/mãe nas relações de cuidado intra-familiar, tal como o sub-título deste artigo propõe. Em minha pesquisa sobre as relações familiares de pacientes de serviço de atenção à saúde mental (Monnerat, 2014) destaquei que cabia predominantemente às mulheres o cuidado e a resolução dos problemas relacionados à esfera familiar. Tendência essa que também foi verificada no campo com militares ${ }^{10}$, nos remetendo, então, a uma possível prevalência referente à existência de uma assimetria nos papéis sociais de gênero relacionados ao cuidado familiar $^{11}$.

\footnotetext{
10 Segundo Adão (2008): “Casar-se com uma mulher que concorde em gerar um núcleo familiar tradicional e que opte por zelar pelo lar e pelos filhos, na maior parte das vezes, em detrimento de seus projetos individuais, como sua formação profissional ou o exercício de uma profissão, seria a forma ideal de garantir o alcance dos objetivos propostos na socialização profissional do militar. Como exemplo, podemos utilizar a necessidade de acompanhar o marido nas transferências pelo território nacional, contingência que seria aceita pelo tipo de esposa acima citado, tido como uma "esposa dedicada".

${ }^{11}$ Segundo Trad "A importância da família nos processos de socialização e subjetivação dos indivíduos e de difusão de práticas culturalmente compartilhadas ou rotinas domésticas é um dado consensuado na literatura. É na família que são transmitidos, às novas gerações, padrões de comportamento, hábitos, valores, padrão de linguagem etc., conformando traços identitários singulares" (Trad, 2010: 44).
} 
As relações de gênero são construídas social e historicamente, fruto de uma incorporação de papéis distintos que homens e mulheres assumem em sociedade (Bourdieu, 1998; Scott, 1989). Bourdieu (1998) discute o papel que a família assume no desenvolvimento das relações de gênero: para este autor a família deve ser considerada como uma instituição de destaque na reprodução da dominação masculina, pois nela se impõe a primeira divisão sexual do trabalho. Chodorow (2002) - que faz um estudo sobre a construção social em que cabe às mulheres maternar - cita a existência de estudos que, ao examinarem a assimetria de gênero no cuidado com os filhos (na qual a mulher assumiria papel de destaque). Ambos sustentam, portanto, que o aprendizado da função de gênero (assim como o desenvolvimento do senso de identificação entre menina e menino) estaria diretamente relacionado a essa assimetria.

Por estarem inseridos em uma sociedade desigual no que tange ao cuidado com a prole, meninas e meninos desenvolveriam diferentes percepções de pertencimento social, levando a uma diferente (e desigual) preparação para as funções da vida adulta entre mulheres e homens. Logo, sob essa perspectiva, os filhos teriam suas capacidades e necessidades relacionadas à paternidade diminuídas, enquanto as filhas teriam suas capacidades (relacionadas à maternidade) supervalorizadas. Essa divisão sexual e familiar do trabalho, baseada no estímulo à maternagem da mãe, em detrimento da participação do pai nas relações afetivas e de cuidado no seio familiar, levaria à reprodução de tal divisão, acabando por reforçar a assimetria de gênero e a manter a mulher como principal responsável pelo cuidado da família (Chodorow, 2002).

Os dados levantados sobre relações de gênero relacionadas ao cuidado familiar nos dois campos estudados estão, então, de acordo com uma antiga tradição intelectual antropológica, da qual posso citar o estudo de Durham (1983: 16), que enfatizou que "o cuidado com as crianças e sua socialização inicial são sempre da competência feminina, e os homens apenas intervém de forma auxiliar ou complementar". Por outro lado, não se pode deixar de considerar, assim como mais uma vez fez Durham (1983: 18), a possibilidade de "modificar culturalmente esse padrão, provendo figuras substitutivas das mães", prática crescente em "sociedades estratificadas, (...) especialmente nas camadas dominantes, [na qual] as mulheres são frequentemente liberadas de pelo menos parte dessa tarefa, com o surgimento das amas-de-leite, babás, preceptores etc”.

Segundo as familiares de pacientes com as quais tive contato, os encargos relacionados ao cuidado com o paciente, com a casa e/ou com demais membros da 
família poderiam ser diminuídos caso essas famílias optassem pela terceirização desses serviços, principalmente a partir da contratação de empregadas domésticas, enfermeiras, cuidadoras e/ou babás. A bibliografia recente sobre "família militar" também segue demonstrando o predomínio de uma estrutura familiar baseada em moldes tradicionais, composta privilegiadamente por famílias nucleares que se organizam em torno do pai provedor e da mãe cuidadora - responsável pelo cuidado da prole e do espaço doméstico.

É interessante destacar que, por outro lado, é possível observar que a bibliografia sobre família presente nas Ciências Sociais vem apontando transformações constantes em seu seio, desde os anos 1960, tal como indicou Peixoto (2007: 11) em seu prefácio ao livro de François Singly:

\begin{abstract}
"A família contemporânea ocidental conheceu numerosas e profundas transformações a partir dos anos 1960. Podemos dizer que, desde então, o modelo ideal de família proposto por T. Parsons na década de 1950 - o casal, legalmente constituído, e seus filhos, tendo o pai como provedor e a mãe como dona-de-casa e responsável pela educação da progenitura - perde vigor e declina à medida que as mulheres se inserem no mercado de trabalho, tendo de conciliar a atividade profissional com a responsabilidade familiar".
\end{abstract}

Partindo das análises etnográficas sobre o tema, pode-se observar que transformações presentes na sociedade mais ampla (no que tange a organização das estruturas familiares e o papel da mulher nas relações de cuidado) vêm proliferando e atingindo, também, a tradicional "família militar" - tal como apontou Adão (2010) ao retratar as relações familiares de oficiais mulheres e de esposas de oficiais que assumem algum posto no mercado de trabalho (e as formas de organização do espaço doméstico e da criação dos filhos desenvolvidas por essas mulheres).

Ao sustentar que o papel assumido pelas mulheres nas relações de cuidado seja um ponto de inflexão entre os dois campos estudados, não pretendo "achata[r] as diferenças, comprimindo-as até caberem todas num mesmo molde que é então utilizado como ponto central de referência quando se fala de família no Brasil", como salientou Corrêa (1982) ao falar sobre o conceito de família patriarcal. Tampouco, pretende-se diminuir o potencial de metamorfose existente nos indivíduos e instituições. O que pretendi mostrar é que, mesmo em universos entendidos pelo senso-comum como tão díspares, aspectos semelhantes estão presentes e podem propiciar um olhar mais abrangente sobre relações familiares nas camadas médias. 
A pesquisa na qual se insere o estudo aqui apresentado (que segue para além dos limites desse artigo), tem ainda como objetivo observar as organizações familiares de oficiais mulheres e de esposas de oficiais inseridas no mercado de trabalho e analisar a existência ou não de possíveis conflitos oriundos dessa crescente profissionalização das mulheres, assim como as estratégias utilizadas por elas para conciliar as suas obrigações de trabalho com as obrigações ditadas pelo tipo ideal de "família militar". Espera-se, com isso, tal como sugeriu Velho (1981: 78/79), “contextualizar a família no quadro mais amplo do universo de representações e da cultura propriamente dita”. Para tanto, cabe realizar um exame aprofundado sobre a configuração da chamada "família militar" no Brasil (e suas possíveis transformações ao longo do tempo), tendo como foco privilegiado o papel social desempenhado por esposas e maridos de oficiais do Exército brasileiro e a influência dos ideais militares na criação dos filhos.

Interessa, portanto, responder à questão de, se em uma "instituição totalizante" (Castro, 2007) como o exército, com ideais fechados no que diz respeito à estrutura familiar de seus membros, também podemos encontrar indícios de um "pluralismo familiar (...) resultado de uma transformação profunda das relações de gênero e da emergência de um equilíbrio entre autonomia individual e pertencimento familiar", como indicado por Peixoto (2007: 12).

Este trabalho, ao invés de conclusões fechadas, dá destaque a desdobramentos analíticos possíveis no percurso da pesquisa em foco. Buscou-se, aqui uma discussão metodológica sobre o estudo de relações familiares em diferentes contextos sociais, assim como observar a existência de possíveis diferenças entre os ideais de família propagados pelos membros dos grupos estudados e as formas de organização familiar presentes de fato. 


\section{Referências}

ADÃO, Maria Cecília de Oliveira. “A Mudança da Tradição: Esposas, Comportamento e Forças Armadas (1964-1998)". Tese de doutorado, São Paulo: Universidade Estadual Paulista Júlio de Mesquita Filho, UNESP, Brasil, 2008.

BILAC, Elisabete Dória. "Sobre as transformações nas estruturas familiares no Brasil. Notas muito preliminares". IN: RIBEIRO, Ivete e RIBEIRO, Ana Clara Torres. Famílias em processos contemporâneos: inovações culturais na sociedade brasileira. São Paulo: Loyola, 1995.

BOURDIEU, Pierre. Razões práticas: sobre a teoria da ação. Campinas: Papirus, 1996. A dominação masculina. Rio de Janeiro: Bertrand Brasil, 1998.

BECKER, Howard. Uma teoria da ação coletiva. Rio de Janeiro: Jorge Zahar, 1977.

CASTRO, Celso. Goffman e os militares: sobre o conceito de instituição total. Militares e política (UFRJ), v. 1, p. 1-7, 2007.

CASTRO, Celso e Leirner, Piero. Antropologia dos militares: reflexões sobre pesquisas de campo. Rio de Janeiro: Editora FGV, 2009.

CHINELLI, Fernanda. "Mulheres de Militares: Família, Sociabilidade e Controle Social". Dissertação de Mestrado, Rio de Janeiro: PPGAS/MN/UFRJ, 2008.

"Pesquisa e aliança: o trabalho de campo com mulheres de militares". IN: Castro, Celso e Leirner, Piero. Antropologia dos militares: reflexões sobre pesquisas de campo. Rio de Janeiro: Editora FGV, 2009.

CHODOROW, Nancy. Psicanálise da maternidade. Uma crítica a Freud a partir da mulher. Rio de Janeiro: Rosa dos Tempos, 2002.

CORRÊA, Mariza. "Repensando a família patriarcal brasileira (notas para o estudo das formas de organização familiar no Brasil)". IN: Almeida, Maria Suely Kofes de (et al). Colcha de retalhos. Estudos sobre família no Brasil. São Paulo: Brasiliense, 1982.

DUARTE, Luiz Fernando. "Nós na família". In: Revista "Ciência Hoje". 2012. http://cienciahoje.uol.com.br/colunas/sentidos-do-mundo/nos-na-familia

DURHAM, Eunice. "Família e reprodução humana". In: Perspectivas antropológicas da mulher. Vol.3. Rio de Janeiro: Zahar, 1983.

LEIRNER, Piero. A Pesquisa de Campo com Militares: algumas questões metodológicas. Trabalho apresentado na ANPOCS, 1996.

LEVI-STRAUSS, Claude. La famille. In Lévi-Strauss, C. Le regard éloigné. Paris: Gallimard, 1979.

MONNERAT, Sílvia. De médico e de louco toda família tem um pouco: um estudo sobre pacientes psiquiátricos e relações familiares. Tese de Doutorado, Rio de Janeiro: PPGAS/MN/UFRJ, 2014.

PEIXOTO, Clarice. "Prefácio - As transformações familiares e o olhar sociológico". In: Singly, François. Sociologia da família contemporânea. Rio de Janeiro: Editora FGV, 2007.

POLLACK, Michael. "Memória, esquecimento e silêncio". In: Estudos Históricos, Rio de Janeiro, vol. 2, n. 3, 1989.

RIBEIRO, Ivete e RIBEIRO, Ana Clara Torres. Famílias em processos contemporâneos: inovações culturais na sociedade brasileira. São Paulo: Loyola, 1995.

SARTI, Cynthia. A família como ordem simbólica. São Paulo: Psicologia USP, 15(3), 11-28, 2004.

SCHUTZ, Alfred. Fenomenologia e relações sociais. Rio de Janeiro: Jorge Zahar, 1979.

SCHUTZ, Alfred. "Sociologia interpretativa". IN: Castro, Celso. Rio de Janeiro: Zahar, 2014.

SILVA, Cristina Rodrigues da. "Explorando o "mundo do quartel". IN: "Pesquisa e aliança: o trabalho de campo com mulheres de militares". IN: Castro, Celso e Leirner, Piero. Antropologia dos militares: reflexões sobre pesquisas de campo. Rio de Janeiro: Editora FGV, 2009.

SCOTT, Joan. Gender: an useful category of historical analyses. Gender and the politics of history. New York: Columbia University Press, 1989. 
TRAD, Leny. "A família e suas mutações: subsídios ao campo da saúde". In: Família contemporânea e saúde: significados, práticas e políticas públicas. TRAD, Leny (org). Rio de Janeiro: Editora Fiocruz, 2010.

VELHO, Gilberto. Individualismo e Cultura: notas para uma antropologia da sociedade contemporânea. Rio de Janeiro: Jorge Zahar, 1981.

VELHO, Gilberto. Um antropólogo na cidade: ensaios de antropologia urbana. Rio de Janeiro: Zahar, 2013.

WEBER, Max. "Os tipos ideais". IN: Castro, Celso. Rio de Janeiro: Zahar, 2014.

Recebido em: 25/03/2015

Aprovado em: 23/05/2015 